\title{
Carbide-free-bainite in low carbon construction steels
}

\author{
A. Yu. Kaletin ${ }^{\dagger, 1,2}$, Yu. V. Kaletina ${ }^{1}$, M. A. Ryzhkov ${ }^{2}$ \\ †akalet@imp.uran.ru
}

\author{
${ }^{1}$ M. N. Miheev Institute of Metal Physics UB RAS, 18 S. Kovalevskaya St., Yekaterinburg, 620990, Russia \\ ${ }^{2}$ Ural Federal University n. a. the first President of Russia B. N. Yeltsin, 19 Mira St., Yekaterinburg, 620002, Russia
}

\begin{abstract}
In this work the structure and mechanical properties of chromium-nickel-molybdenum steels with a carbon content of 0.1 to $0.2 \%$ after austenitization and slow continuous cooling in the bainitic region at a rate of about $5^{\circ} \mathrm{C} / \mathrm{min}$ were investigated. It was shown that at a carbon content of about $0.10 \ldots 0.15 \%$ after such heat treatment, a carbide-free bainite structure is formed in steel, which is a two-phase mixture of bainitic ferrite and residual austenite supersaturated with carbon. Using transmission electron microscopy, the features of the formed bainitic ferrite and the distribution of retained austenite, the amount of which ranged from 10 to $14 \%$, were studied. Using X-ray phase analysis, the carbon content in the retained austenite was determined, which turned out to be equal to $0.8 \ldots 0.9 \% \mathrm{C}$. An increase in carbon content up to $0.2 \%$ in such steels leads to the precipitation of carbide particles during bainitic transformation with continuous cooling. After additional doping with silicon in an amount of about $1 \%$ in the steel of such an alloying system with $0.2 \% \mathrm{C}$, the formation of carbides is almost completely suppressed and carbide-free bainite is formed, while the amount and degree of enrichment of retained austenite in carbon slightly increases. Comparison of the mechanical properties of the investigated low-carbon steels showed that at approximately the same level of strength, steels with carbide-free bainite have a higher level of toughness compared to steel containing carbide precipitates. Retained austenite in carbide-free bainite is substantially carbon enriched and contains a significant portion of the total carbon content in steel.
\end{abstract}

Keywords: structural steels, carbide-free bainite, residual austenite, mechanical properties, impact strength.

УДК: 669.14.018.29:539.4.015

\section{Бескарбидный бейнит в низкоуглеродистых конструкционных сталях}

\author{
Калетин А. Ю. ${ }^{\dagger, 1,2}$, Калетина Ю. В. ${ }^{1}$, Рыжков М. А. ${ }^{2}$ \\ ${ }^{1}$ Институт физики металлов им. М.Н. Михеева, УрО РАН, ул. С. Ковалевской, 18, Екатеринбург, 620990, Россия \\ ${ }^{2}$ Уральский федеральный университет им. первого президента России Б. Н. Ельцина, \\ ул. Мира, 19, Екатеринбург, 620002, Россия
}

В настоящей работе исследована структура и определены механические свойства хромоникельмолибденовых сталей с содержанием углерода от 0.1 до $0.2 \%$ после аустенитизации и медленного непрерывного охлаждения в бейнитной области со скоростью около $5^{\circ} \mathrm{C} /$ мин. Показано, что при содержании углерода около $0.10 \ldots 0.15 \%$ после такой термообработки в стали образуется структура бескарбидного бейнита, представляющего собой двухфазную смесь бейнитного феррита и пересыщенного углеродом остаточного аустенита. С применением метода просвечивающей электронной микроскопии исследованы особенности образовавшегося бейнитного феррита и распределение остаточного аустенита, количество которого составляло от 10 до 14\%. С помощью рентгеноструктурного фазового анализа определено содержание углерода в остаточном аустените, которое оказалось равным 0.8...0.9\% С. Повышение содержания углерода до $0.2 \%$ в таких сталях приводит к выделению карбидных частиц в процессе бейнитного превращения при непрерывном охлаждении. После дополнительного легирования кремнием в количестве около $1 \%$ в стали такой системы легирования с $0.2 \%$ С карбидообразование практически полностью подавляется и наблюдается образование бескарбидного бейнита, при этом количество и степень обогащения остаточного аустенита по углероду несколько увеличивается. Сравнение механических свойств исследованных низкоуглеродистых сталей показало, что при примерно одинаковом уровне прочности стали с бескарбидным бейнитом обладают более высоким уровнем ударной вязкости по сравнению со сталью, содержащей карбидные выделения. Остаточный аустенит в бескарбидном бейните существенно обогащен по углероду и содержит значительную часть от общего содержания углерода в стали.

Ключевые слова: конструкционные стали, бескарбидный бейнит, остаточный аустенит, механические свойства, ударная вязкость. 


\section{1. Введение}

В течение значительного времени вопросы изучения особенностей бейнитного превращения в конструкционных сталях продолжают привлекать внимание ученых в различных странах [1-8]. Особый интерес вызывает возможность получения в результате термической обработки в промежуточном интервале температур, ограниченном сверху областью диффузионного перлитного, а снизу - мартенситного превращения, структуры бескарбидного бейнита (БКБ), представляющего собой двухфазную феррито-аустенитную смесь, состоящую из $\alpha$-фазы и пересыщенного по углероду остаточного аустенита (OA). Интерес к изучению БКБ обусловлен тем, что стали с такой структурой обладают высоким сочетанием прочности и ударной вязкости $[3-6,9]$. Кроме того, показано, что среднеуглеродистые стали со структурой бескарбидного бейнита после изотермической закалки имеют повышенное сопротивление изнашиванию $[10,11]$, а также проявляют повышенную статическую и циклическую трещиностойкость [12].

Однако большинство работ, посвященных проблеме изучения особенностей бескарбидного бейнита, проводились на конструкционных среднеуглеродистых и высокоуглеродистых сталях, легированных элементами, в первую очередь кремнием или алюминием, эффективно подавляющими образование карбидов в промежуточной области температур [12-19]. При этом достаточно много работ посвящено исследованию бейнита, образующегося в изотермических условиях в конструкционных среднеи высокоуглеродистых конструкционных сталях $[4,6,10,13-15,18,19]$. Исследований БКБ в конструкционных легированных сталях с невысоким содержанием углерода имеется существенно меньше.

В работе [16] на хромоникельмолибденовой стали было показано, что уменьшение содержания углерода до $0.10 \%$ позволяет исключить карбидообразование в ходе промежуточного превращения при непрерывном охлаждении и приводит к образованию бескарбидного бейнита. Целью настоящей работы было изучение возможности получения бескарбидного бейнита в конструкционных сталях системы легирования Х2Н2МФ с низким содержанием углерода, исследование роли остаточного аустенита в них, а также механические свойства таких сталей после непрерывного охлаждения в бейнитном интервале температур.

\section{2. Материалы и методы исследования}

Исследовали структуру и свойства легированных сталей, химический состав которых приведен в Табл. 1. Для получения бейнитной структуры заготовки исследуемых сталей нагревали на $870^{\circ} \mathrm{C}$ с выдержкой 30 мин. Затем образцы охлаждали с печью с постоянной скоростью $V_{\text {охл }}=5^{\circ} \mathrm{C} /$ мин. Структуру сталей изучали электронномикроскопическим методом на микроскопе JEM200СX на фольгах, вырезанных из соответствующих образцов, приготовленных по стандартной методике. Количество остаточного аустенита измеряли магнитометрическим методом. Механические свойства определяли при комнатной температуре статическим растяжением пятикратных образцов с диаметром рабочей части 5 мм. Ударную вязкость определяли на образцах типа I по ГОСТ 9454-78. Для определения параметра решетки остаточного аустенита на аппарате ДРОН 3.0 в Ка излучении железа снимали линию (311) $\gamma$. Полученные данные использовали для расчета содержания углерода в остаточном аустените по методике [7].

\section{3. Результаты и обсуждение}

Конструкционные стали с системой легирования типа Х2Н2МФ и содержанием углерода $0.35-0.45 \%$ применяются в промышленности для изготовления тяжелонагруженных деталей и обладают повышенной устойчивостью аустенита при охлаждении в перлитной области. Однако в производстве при закалке в масло крупных изделий из таких сталей в центральных участках в результате замедленного непрерывного охлаждения в достаточно широком интервале промежуточного превращения неизбежно образуется бейнитная структура, состоящая из участков феррита глобулярной и реечной формы, а также значительным количеством карбидов цементитного типа и незначительным количеством остаточного аустенита. В исследованных в настоящей работе хромоникельмолибденовых сталях $10 \mathrm{X} 2 \mathrm{H} 2 \mathrm{M} \Phi, 15 \mathrm{X} 2 \mathrm{H} 2 \mathrm{M} \Phi$ и $20 \mathrm{X} 2 \mathrm{H} 2 \mathrm{M} \Phi$ при медленном охлаждении от температуры аустенитизации $870^{\circ} \mathrm{C}$ с печью $\left(V_{\text {охл }}=5^{\circ} \mathrm{C} /\right.$ мин $)$ формируется полностью бейнитная структура. Электронно-микроскопическое исследование сталей 10Х2Н2МФ и 15Х2Н2МФ показало (Рис. 1a,b), что характерной особенностью структуры бейнита в этих сталях является полное отсутствие карбидов.

Табл. 1. Химический состав исследованных сталей, масс.\%.

Tabl. 1. The chemical composition of the studied steels, wt.\%.

\begin{tabular}{|c|c|c|c|c|c|c|c|c|c|}
\hline Сталь / Steel & $\mathrm{C}$ & $\mathrm{Cr}$ & $\mathrm{Ni}$ & $\mathrm{Mn}$ & $\mathrm{Si}$ & $\mathrm{Mo}$ & $\mathrm{V}$ & $\mathrm{S}$ & $\mathrm{P}$ \\
\hline $10 \mathrm{X} 2 \mathrm{H} 2 \mathrm{M} \Phi / \mathrm{Fe}-0.10 \mathrm{C}-2 \mathrm{Cr}-2 \mathrm{Ni}-\mathrm{Mo}-\mathrm{V}$ & 0.10 & 2.15 & 2.47 & 0.42 & 0.39 & 0.41 & 0.15 & 0.018 & 0.013 \\
\hline $15 \mathrm{X} 2 \mathrm{H} 2 \mathrm{M} \Phi / \mathrm{Fe}-0.15 \mathrm{C}-2 \mathrm{Cr}-2 \mathrm{Ni}-\mathrm{Mo}-\mathrm{V}$ & 0.14 & 2.05 & 2.33 & 0.56 & 0.21 & 0.38 & 0.17 & 0.026 & 0.016 \\
\hline $20 \mathrm{X} 2 \mathrm{H} 2 \mathrm{M} \Phi / \mathrm{Fe}-0.20 \mathrm{C}-2 \mathrm{Cr}-2 \mathrm{Ni}-\mathrm{Mo}-\mathrm{V}$ & 0.20 & 2.02 & 2.27 & 0.61 & 0.30 & 0.36 & 0.11 & 0.025 & 0.018 \\
\hline $20 \mathrm{X} 2 \mathrm{H} 2 \mathrm{CM} / \mathrm{Fe}-0.20 \mathrm{C}-2 \mathrm{Cr}-2 \mathrm{Ni}-\mathrm{Si}-\mathrm{Mo}-\mathrm{V}$ & 0.19 & 1.86 & 2.21 & 0.41 & 1.06 & 0.42 & 0.13 & 0.017 & 0.012 \\
\hline
\end{tabular}


Морфология бейнита практически одинаковая, в ней наблюдаются кристаллы бейнитного феррита глобулярной и реечной формы и остаточный аустенит, наблюдаемый на темнопольных изображениях в рефлексе $(200 \gamma)$. Количество остаточного аустенита в этих сталях составляет $10-14 \%$ и он располагается в основном в виде достаточно тонких прослоек между рейками бейнитного феррита. Таким образов, в этих сталях в процессе медленного непрерывного охлаждения образуется полностью бескарбидный бейнит. Исследование тонкой структуры стали 20Х2Н2МФ показало, что в ней наблюдается процессы выделения карбидной фазы (Рис. 2), а количество остаточного аустенита составляет $11 \%$. Карбидные выделения находятся в основном в участках между рейками бейнитного феррита, а также в виде скоплений на изолированных участках глобулярной формы, то есть там, где процесс обогащения непревращенного аустенита происходил в наибольшей степени.

Наблюдаемые различия в бейнитной структуре сталей позволяют заключить, что содержание углерода в сталях такой системы легирования, обеспечивающим образование бескарбидного бейнита при непрерывном охлаждении, составляет $0.15 \%$ С и ниже. Чтобы обеспечить бейнитную прокаливаемость и получение бескарбидного бейнита в стали с содержанием $0.2 \%$, необходимо дополнительно легировать ее кремнием, подавляющим процессы карбидообразования в промежуточном интервале температур. В работе была исследована сталь 20Х2Н2СМФ, в которой после термообработки в бейнитном интервале отсутствуют карбидные выделения и образуется полностью бескарбидный бейнит.

Исследование механических свойств показало (Табл. 2), что все стали с бейнитной структурой, образовавшейся при непрерывном охлаждении, обладают примерно одинаковым уровнем прочности.

При этом ударная вязкость сталей 10Х2Н2МФ, 15Х2Н2МФ и 20Х2Н2СМФ, в которых наблюдается полностью бескарбидный бейнит, составляет от 1.10 до 1.25 МДж/м² и заметно выше ударной вязкости стали 20Х2Н2МФ, в которой наблюдается бейнитная структура с выделениями карбидной фазы -0.75 МДж/м². При этом наблюдается различие в пластичности: если для стали $20 \mathrm{X} 2 \mathrm{H} 2 \mathrm{CM} \Phi \delta=16 \%$ и $\psi=56 \%$, то для стали $20 \mathrm{X} 2 \mathrm{H} 2 \mathrm{M} \Phi$ с карбидами $\delta=11 \%$ и $\psi=51 \%$. Отметим также, что как и в наших более ранних работах $[9,16]$, характер разрушения бескарбидного бейнита (стали $10 \mathrm{X} 2 \mathrm{H} 2 \mathrm{M} \Phi, 15 \mathrm{X} 2 \mathrm{H} 2 \mathrm{M} \Phi$ и 20Х2Н2СМФ) и бейнита с выделениями цементита (сталь 20Х2Н2МФ) заметно отличается: если в первом случае это в основном смешанное разрушение в виде сочетания вязкого (путем слияния микропор) и квазискола, то во втором случае

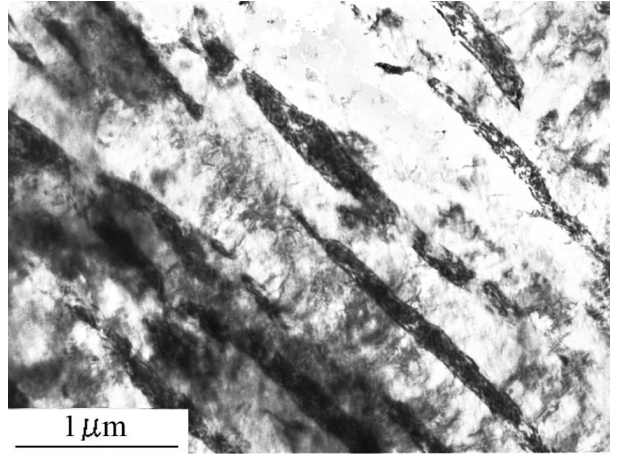

a

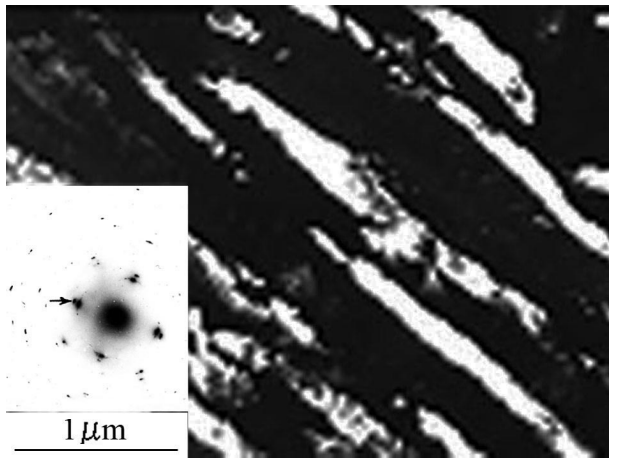

b

Рис. 1. Микроструктура стали 10Х2Н2МФ после непрерывного охлаждения со скоростью $V_{\text {охл }}=5^{\circ} \mathrm{C} /$ мин: светлопольное изображение (a); темнопольное изображение в рефлексе (002) $\gamma$; на электронограмме рефлекс (002) $\gamma$ указан стрелкой (b).

Fig. 1. The microstructure of steel Fe- $0.10 \mathrm{C}-2 \mathrm{Cr}-2 \mathrm{Ni}-\mathrm{Mo}-\mathrm{V}$ after continuous cooling at the rate of $V_{\text {cool }}=5^{\circ} \mathrm{C} / \mathrm{min}$ : bright field image (a); dark-field image in the $(002) \gamma$ reflex; in the electron diffraction pattern the (002) $\gamma$ reflex is indicated by the arrow (b).

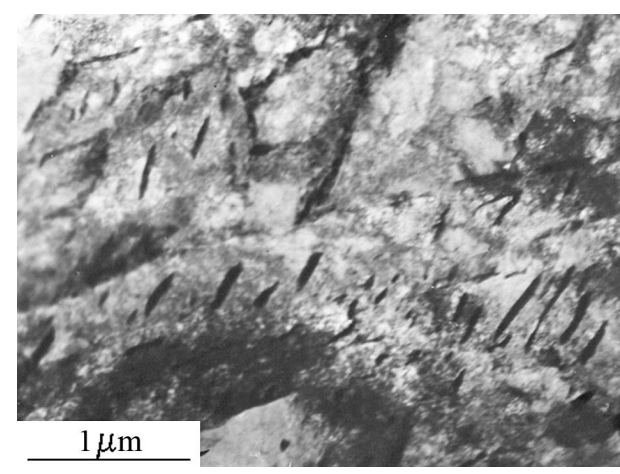

a

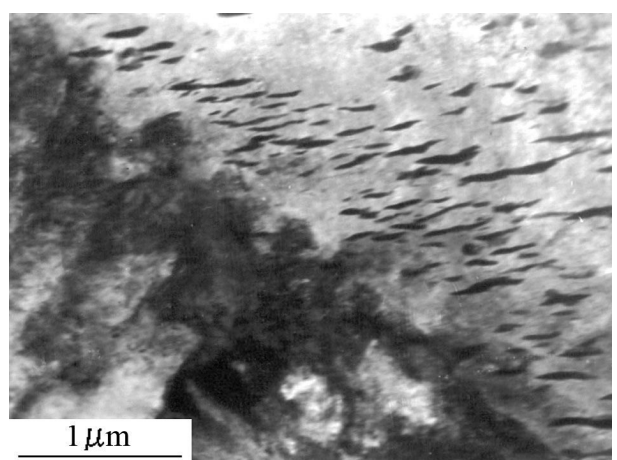

$\mathrm{b}$

Рис. 2. Микроструктура стали $20 \mathrm{X} 2 \mathrm{H} 2 \mathrm{MФ}$ после непрерывного охлаждения со скоростью $V_{\text {охл }}=5^{\circ} \mathrm{C} / \mathrm{M} и н .:$ светлопольное изображение $(\mathrm{a}, \mathrm{b})$.

Fig. 2. The microstructure of steel Fe-0.20C-2Cr-2Ni-Mo-V after continuous cooling at a rate of $V_{\text {cool }}=5^{\circ} \mathrm{C} / \mathrm{min}$ : bright field image (a, b). 
Табл. 2. Влияние содержания углерода на количество остаточного аустенита $\mathrm{A}_{\text {ост }}$ и механические свойства сталей после непрерывного охлаждения от $870^{\circ} \mathrm{C}$ в бейнитном интервале температур $\left(V_{\text {охл }}=5^{\circ} \mathrm{C} /\right.$ мин $)$.

Tabl. 2. The effect of carbon content on the amount of retained austenite $\mathrm{A}_{\text {ret }}$ and the mechanical properties of steels after continuous cooling from $870^{\circ} \mathrm{C}$ in the bainitic temperature range $\left(V_{\text {cool }}=5^{\circ} \mathrm{C} / \mathrm{min}\right)$.

\begin{tabular}{|c|c|c|c|c|c|c|c|}
\hline \multirow{2}{*}{$\begin{array}{c}\text { Сталь } \\
\text { Steel }\end{array}$} & \multirow{2}{*}{$\begin{array}{l}\sigma_{\text {в }}, \mathrm{M \Pi а} \\
\sigma_{\text {в }}, \mathrm{MPa}\end{array}$} & \multirow{2}{*}{$\begin{array}{c}\mathrm{KCU}, \\
\mathrm{MД} / \mathrm{M}^{2} \\
\mathrm{KCU} \\
\mathrm{MJ} / \mathrm{m}^{2}\end{array}$} & \multirow{2}{*}{$\begin{array}{l}\text { Твердость, } \\
\text { HRC } \\
\text { Hardness, } \\
\text { HRC }\end{array}$} & \multirow{2}{*}{$\begin{array}{l}\mathrm{A}_{\text {ocr, }}, \% \\
\mathrm{~A}_{\text {ret }}, \%\end{array}$} & \multicolumn{2}{|c|}{$\begin{array}{c}\text { Содержание углерода, масс.\% } \\
\text { Carbon content, wt.\% }\end{array}$} & \multirow{2}{*}{$\begin{array}{c}\text { Доля } \\
\text { углерода в } \mathrm{A}_{\text {ост }} \% \\
\text { Share } \\
\text { carbon in } \mathrm{A}_{\text {ret }} \%\end{array}$} \\
\hline & & & & & $\begin{array}{l}\text { в стали } \\
\text { in steel }\end{array}$ & $\begin{array}{l}\text { B } A_{\text {oct }} \\
\text { in } A_{\text {ret }}\end{array}$ & \\
\hline $\begin{array}{c}10 \mathrm{X} 2 \mathrm{H} 2 \mathrm{M} \Phi \\
\text { Fe-0.10C-2Cr-2Ni-Mo-V }\end{array}$ & 1240 & 1.10 & 37 & 10 & 0.10 & 0.8 & 80 \\
\hline $\begin{array}{c}\text { 15X2H2M } \Phi \\
\text { Fe-0.15C-2Cr-2Ni-Mo-V }\end{array}$ & 1190 & 1.25 & 38 & 14 & 0.14 & 0.9 & 90 \\
\hline $\begin{array}{c}20 \mathrm{X} 2 \mathrm{H} 2 \mathrm{M} \Phi \\
\mathrm{Fe}-0.20 \mathrm{C}-2 \mathrm{Cr}-2 \mathrm{Ni}-\mathrm{Mo}-\mathrm{V}\end{array}$ & 1250 & 0.75 & 39 & 11 & 0.20 & 0.8 & 44 \\
\hline $\begin{array}{c}\text { 20X2H2CM } \Phi \\
\text { Fe-0.20C-2Cr-2Ni-Si-Mo-V }\end{array}$ & 1280 & 1.10 & 39 & 16 & 0.19 & 1.1 & 92 \\
\hline
\end{tabular}

это в основном внутризеренное разрушение квазисколом. Обращает на себя внимание и тот факт, что в первых трех сталях без кремния остаточный аустенит сильно пересыщен по углероду - содержание углерода в остаточном аустените примерно одинаково и составляет $0.8-0.9 \%$ С. Дополнительное легирование стали кремнием привело к еще большему пресыщению ОА по углероду и составило $1.1 \% \mathrm{C}$. Сравнивая общее содержание углерода в стали и полученное содержание углерода в остаточном аустените и количество этого остаточного аустенита, можно вычислить долю углерода, содержащегося в этом остаточном аустените от общего содержания углерода в стали.

Оказалось (Табл. 2, последняя колонка), что в случае образования бескарбидного бейнита подавляющая часть углерода стали находится в остаточном аустените 80 - 92\%, при этом стали обладают повышенной ударной вязкостью. В случае стали с бейнитом, содержащим карбидные выделения, доля углерода в ОА составляет всего $44 \%$, то есть более половины углерода находится в бейнитном феррите и цементите, при этом ударная вязкость заметно ниже. Из этого следует, что для исследованных низкоуглеродистых хромоникельмолибденовых сталей, в которых бейнитная структура образуется при медленном непрерывном охлаждении, доля углерода в остаточном аустените может характеризовать морфологические особенности структурных составляющих (бескарбидный бейнит или бейнит с карбидными выделениями), и уровень ударной вязкости стали.

\section{4. Выводы}

1. При медленном непрерывном охлаждении в промежуточном интервале температур в хромоникельмолибденовых сталях, содержащих 0.10-0.15\% C, образуется бескарбидный бейнит, представляющий собой феррито-аустенитную структуру, не содержащую выделений карбидной фазы. Повышение содержания углерода в таких сталях до $0.20 \%$ С приводит к образованию структуры бейнита, содержащего заметное количество мелкодисперсной карбидной фазы.
2. Легирование хромоникельмолибденовой стали с $0.2 \%$ С кремнием в количестве около $1 \%$ позволяет исключить карбидообразование в ходе промежуточного превращения при непрерывном охлаждении и приводит к образованию полностью бескарбидного бейнита.

3. Остаточный аустенит в бескарбидном бейните низкоуглеродистых хромоникельмолибденовых сталей существенно обогащен по углероду и содержит значительную часть от общего содержания углерода в стали. При содержании в остаточном аустените бескарбидного бейнита более $80 \%$ углерода сталь при почти одинаковой прочности обладает заметно более высоким уровнем ударной вязкости, чем сталь с бейнитом, содержащим карбиды.

Благодарности/Acknowledgements. Работа выполнена в рамках государственного задания МИНОБРНАУКИ России (тема «Давление», № АААА-А18-118020190104-3 и тема «Структура», № ААAА-А18-118020190116-6 при частичной поддержке Комплексной программы УрО РАН проект №18-20-2-24 и проекта РФФИ №20-03-00056). / The study was performed within the state assignment of Ministry of Science and Higher Education of the Russian federation (theme "Pressure" No. AAAA-A18-118020190104-3 and theme "Structure" No. AAAA-A18-118020190116-6 with partial support from the Comprehensive Program of the Ural Branch of the Russian Academy of Sciences project No. 18-20-2-24 and RFBR project No. 20-03-00056).

\section{Литература/References}

1. C. Hofer, H. Leitner, F. Winkenhofer, H. Clemens, S. Primig. Mater. Char. 102, 85 (2015). Crossref

2. H.K.D.H. Bhadeshia. Bainite in Steels: Theory and Practice, 3d ed. London, CRC Press (2015) 616 p.

3. F.G. Caballero, H.K.D.H. Bhadeshia. Current Opinion in Solid State and Materials Science DK. 8, 251 (2004). Crossref

4. C. Garcia-Mateo, F. G. Caballero, H. K. D.H. Bhadeshia. Materials Science Forum. 500, 495 (2005). 
5. M. Soliman, H. Mostafa, A.S. El-Sabbah, H. Palkovski. Mater. Sci.Eng. A. 527, 7706 (2010). Crossref

6. X.Y. Long, J. Kang, B. Ly, F.C. Zhang. Materials and Design. 64, 237 (2014). $\underline{\text { Crossref }}$

7. Z. Bojarski, T. Bold. Acta Met. 22 (10), 1223 (1974). Crossref

8. J.C. Hell, M. Dehmas, S. Allain, J.M. Prado. ISIJ international. 51, 1724 (2011). Crossref

9. Yu. M. Kaletin, A. G. Ryzhkov, A. Yu. Kaletin. Izvestiy Vuzov. Chernaya Metallurgya. 6, 96 (1989). (in Russian) [Ю.М. Калетин, А.Г. Рыжков, А.Ю. Калетин. Известия Вузов. Черная металлургия. 6, 96 (1989).]

10. A. V. Makarov, L. G. Korshunov, I. L. Solodova. Friction and wear. 21, 501 (2000). (in Russian) [А. В. Макаров, Л.Г. Коршунов, И.Л. Солодова. Трение и износ. 21, 501 (2000).]

11. A. V. Makarov, V.M. Schastlivtsev, T.I. Tabatchikova. Deformation and fracture of materials. 6, 1 (2010). (in Russian) [А.В. Макаров, В.М. Счастливцев, Т.И. Табатчикова. Деформация и разрушение материалов. 6, 1 (2010).]

12. M.N. Georgiev, A.Yu. Kaletin, Yu.N. Simonov, V.M. Schastlivtsev. Phys. Metals Metallogr. 1, 113 (1990). (in Russian) [М.Н. Георгиев, А.Ю. Калетин, Ю.Н. Симонов, В.М. Счастливцев. ФММ. 1, 113 (1990).]

13. V.M. Schastlivtsev, Yu. V. Kaletina, E.A. Fokina, A. Yu. Kaletin. Phys. Metals Metallogr. 115, 962 (2014). (in Russian) [В.М. Счастливцев, Ю.В. Калетина, Е. А. Фокина, А. Ю. Калетин. ФММ. 115, 962 (2014).] Crossref

14. V.M. Schastlivtsev, Yu. V. Kaletina, E.A. Fokina, A. Yu. Kaletin. Phys. Metals Metallogr. 115, 1052 (2014). (in Russian) [B.М. Счастливцев, Ю.В. Калетина, Е. А. Фокина, А. Ю. Калетин. ФММ. 115, 1052 (2014).] Crossref

15. A. Yu. Kaletin, Yu. V. Kaletina. Phys. Solid State. 57, 56 (2015). (in Russian) [А. Ю. Калетин, Ю.В. Калетина. ФТТ. 57, 56 (2015).]

16. A. Yu. Kaletin, A. G. Ryzhkov, Yu. V. Kaletina. Phys. Metals Metallogr. 116, 114 (2015). (in Russian) [А. Ю. Калетин, А. Г. Рыжков, Ю. В. Калетина. ФММ. 116, 114 (2015).] Crossref

17. Yu. N. Simonov, M. Yu. Simonov, D.O. Panov, V.P. Vylezhnev, A. Yu. Kaletin. Metal Science and Heat Treat. Metals. 2, 4 (2016). (in Russian) [Ю.Н. Симонов, М.Ю. Симонов, Д.О. Панов, В.П. Вылежнев, А. Ю. Калетин. МиТОМ. 2, 4 (2016).]

18. D. O. Panov, Yu. N. Simonov, P. A. Leontiev, A. Yu. Kaletin. Metal Science and Heat Treat. Metals. 2, 13 (2016). (in Russian) [Д. О. Панов, Ю.Н. Симонов, П.А. Леонтьев, А. Ю. Калетин. МиТОМ. 2, 13 (2016).]

19. A. Yu. Kaletin, Yu. V. Kaletina. Phys. Metals Metallogr. 119, 946 (2018). (in Russian) [А.Ю. Калетин, Ю.В. Калетина. ФММ. 119, 946 (2015).] Crossref 